\title{
Assessment Of Depression Among The Dentists Of Karachi By Using AKUAD Scale
}

\author{
Kiran Fatima Mehboob Ali Bana, Zubair Ahmed Abbassi, Samina Saleem
}

ABSTRACT:

Objective: To assess the anxiety and depression among the dentists of Karachi by using AKUADS.

Study Design and Setting: It was a cross sectional study design conducted in Karachi.

Methodology: The calculated sample size was 293. The data was collected over a period of 3 months with the help of validated Questionnaire of Aga Khan University Anxiety and Depression Scale (AKUADS). Informed consent was taken and rationale was explained to all the participants before commencement of this study.

Results: Our study focused on sample of 234 . The response rate was $79.8 \%$. The anxiety and depression was prevalent in $67.9 \%$ of dentists from Karachi. Males and unmarried/single dentists were more depressed than females and married dentists. The 24-30 years of dentists having more than five years of professional experience and were working more than 40 hours per week were found to be more depressed $n=82(72.56 \%)$ than the dentists who worked less than forty hours per week; $n=77(63.6 \%)$ and calculated $P$ value was 0.093 . When analyzing the association between anxiety and depression and working sector; dentists who worked in private sector $(n=81) 71.05 \%$ were found to be more depressed than the dentists worked in Public sector and the calculated P-value was 0.197.

Conclusion: The study rendered substantial data about unexpectedly high prevalence of anxiety and depression among the sample of dentists from Karachi. It was inferred from the study that experience in professional field, age of dentists, more than 40 hours working per week and working in private sector have been associated with anxiety and depression among the dentists of Karachi.

Keywords: AKUADS, Anxiety, Dentists, Depression

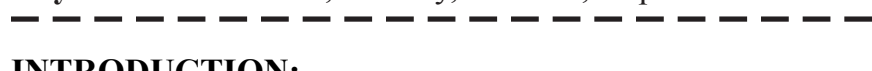

\section{INTRODUCTION:}

Worldwide, every individual is well known with the terms "Anxiety" and "Depression". There is not a single place left in this world which is devoid of depression and anxiety ${ }^{1,2}$ and it causes negative brunt on professional and personal life of an individual. ${ }^{3}$ The condition of agony, panic or excessive worries results in unexpected and unpleasant physical and psychological symptoms is known as anxiety, which may lead to undesirable physical and psychological symptoms and unpleasant state. ${ }^{4}$ The lack of interest in daily activities with low spirits is known as depression. ${ }^{5}$ To address this problem, satisfactory mental health is the right of every individual on this earth. Mental health is an iceberg phenomenon which is under-diagnosed, under estimated and under treated in most part of the world. ${ }^{1}$ Healthcare physician are facing more challenges towards their job and are at higher risk of having mental health issues which exacerbates anxiety, depression. There is ample literature

I Kiran Fatima Mehboob Ali Bana

I Senior Lecturer Department of Community and Preventive

Dentistry, Bahria University of Medical and Dental College

I E-mail: kiranbana291@gmail.com

I Zubair Ahmed Abbassi

I Head of the Oral and Maxillofacial Surgery

I Jinnah Sindh Medical University Karachi

I Samina Saleem

In-dependent Researcher

Karachi University

Received: 08-02-2019

Accepted: 14-05-2019 available on mental health status in developing world stating that worldwide two third burden of mental health problems is in developing countries and will become more worsen if not addressed on a timely manner. ${ }^{6}$

Like Medicine, dentistry itself is a stressful profession and the stress commences from dental schools going way beyond their professional lives. ${ }^{7}$ Upon taking step in professional life dentists bump into multiple stressors resulting in deterioration of physical and mental health. Occupational stress in dentistry was highlighted worldwide due to the competitive job market, demands of experienced, trained and qualified professionals, day to day technical innovations and competition to meet the benchmark of accreditations bodies in all the teaching and management Institutes ${ }^{8}$. Beside the pressure of occupational stress, there is a huge burden to improve the quality of life through handsome salary, sound mind and body, professional and personal development. All these stressors have a negative impact on personal and professional life of dentists. ${ }^{9-12}$ In developing countries like Pakistan; there were some studies conducted which revealed the prevalence of anxiety and depression among the habitants of Karachi was $25 \%$ to $30 \%{ }^{13,14}$ According to Khuwaja AK (2004); anxiety and depression in family practitioners was high as compare to general population. ${ }^{3}$ From Rawalpindi and Islamabad $38.8 \%$ of dentists were severely stressed out. ${ }^{15}$ Another study conducted at Islamic International Dental Hospital Islamabad to assess the stress and its associated factors among the dentists of only one Institute. ${ }^{16}$ During 2005-2015, the prevalence of depression was augmented 
and reached up to $18 \%$ according to World Health Organization. ${ }^{17}$

To accept the mental health problems in an individual and equipped for screening or treatment is not even welcomed by health care professionals and this is even not a routine practiced to assess the mental health problems including depression and anxiety. ${ }^{1}$ Many a times; mental health problems of healthcare professionals are disregarded not only by general public but even from physician's themselves ${ }^{1}$. In developed countries like Canada, USA; significant work has been performed to assess the mental health status of healthcare personnel and more should be done in developing countries. ${ }^{1,18}$

There is not such framework developed and practiced in developing countries to assess the mental health issues mainly depression and anxiety in general population. According to literature; there is not even a single study conducted in Karachi, Pakistan; which assessed the prevalence of anxiety and depression among dentists by utilizing Aga Khan University Anxiety and Depression Scale (AKUADS) and this was indeed the rationale of this study. It was hypothesized that there was an impact of age, gender, marital status, place of working and years of experience since graduation over anxiety and depression among dentist of Karachi.

\section{METHODOLOGY:}

It was a cross sectional study conducted in Karachi from April to June-2017.The dental Surgeons working in metropolitan city of Karachi, Pakistan were the study population. The sample size was 293 and was calculated by using the standard formula with the help of $20 \%$ prevalence. ${ }^{19}$ By convenience sampling, self-administered questionnaire of AKUADS was distributed among all participants after informed consent was obtained. The general Dental practitioners having greater than one year of experience in any sub specialty of dentistry were included in this study. House surgeons and general dental practitioner who suffered from depressive symptoms for less than six weeks and had bereavement in the last six weeks were excluded from the study. (AKUADS) was formulated exclusively for screening in psychiatric setting of Pakistan. It is used in Primary Health Care Setting and integrates basic somatic metaphors of depressive disorder which are culturally apposite in the setting of our society. ${ }^{5,20}$ AKUAD Scale consists of 25 items. The score $>20$ indicates cut-off for the presence of anxiety and depression. ${ }^{20,21}$ Other questions were also added in AKUADS questionnaire to assess socio-demographic and professional work load. Socio demographic variables included were age, gender, marital status, years of experience. Professional characteristics included were working hours per week and place of working such as public or private sector. The study was conducted after approval from ERB, BUMDC; reference number 209/116. Participants were assured of their confidentiality hence they were encouraged to give a complete honest response. The data was analyzed on Statistical Package for the Social Sciences (SPSS) version 23. ${ }^{22}$ Association between different variables were assessed through application of chi square $\left(\div^{2}\right)$.P value less than 0.05 was considered as statistically significant.

\section{RESULTS:}

The total number of inducted participants was 293 from which 234 dentists filled the questionnaire completely hence included for data collection and calculated response rate was $79.8 \%$. The frequency of anxiety and depression among the sample of dentists from Karachi was found to be $67.9 \%$. From the total number of participants there were $n=113$ $(48.3 \%)$ male and $\mathrm{n}=121(51.7 \%)$ female dentists. The age stratum was divided into 24-30 years, 31-40 years and more than 41 years of age. Majority of dentists were between $24-$ 30 years of age; $n=121(51.7 \%), n=81(34.6 \%)$ were fall under the age bracket of 31-40 years and least number of dentists $\mathrm{n}=32(13.7 \%)$ were of more than 41 years of age. There were $\mathrm{n}=127(54.3 \%)$ unmarried dentists and $\mathrm{n}=107$ $(45.7 \%)$ married dentists from the entire sample. The experience period of dentistry profession was again divided into three groups. Most of the dentists; $\mathrm{n}=101(43.2 \%)$ had less than five years of experience; $n=96(41.0 \%)$ had more than five years of experience and $n=37(15.8 \%)$ had more than 10 years of professional experience. Depression was found to be highest in second group of more than five years of professional experience; $\mathrm{n}=69(71.8 \%)$ and the calculated $P$ value $=0.010$. Majority of dentists; $n=121(51.7 \%)$ worked less than forty hours per week and $n=113(48.3 \%)$ were working more than forty hours per week. When analyzing the association between anxiety and depression and working sector; dentists who worked in private sector (private teaching Institutes, clinics) ( $\mathrm{n}=81$ ) $71.05 \%$ were found to be more depressed than the dentists worked in Public sector (Public teaching Institutes, hospitals) and the calculated P-value was 0.197 . Therefore we accept the research hypothesis. (Table-1, Graph-1 and Graph-2).

\section{DISCUSSION:}

In this study; the anxiety and depression was prevalent in $67.9 \%$ of dentists by using AKUADS; which was quite high as compare to the study conducted in Rawalpindi and Islamabad, in which $38.8 \%$ dentists were severely depressed. ${ }^{15}$ According to the studies conducted in Lahore; on HADS Scale $1.0 \%$ and $7.2 \%$ doctors were suffering from severe depression and anxiety and $24.8 \%$ and $34 \%$ doctors were suffered from mild to moderate depression and anxiety respectively ${ }^{1}$. The prevalence was found to be $39 \%$ by using the same AKUADS study tool among family practitioners of Karachi ${ }^{3}$ and these results were relatively elevated than the anxiety and depression score among the natives of Karachi by using similar AKUADS instrument in community based surveys ${ }^{14,23}$; these results were analogous with the study conducted in UK 2014 which depicted that dentists in UK recorded a higher average anxiety score of (53\%) 
Table-1: Depression and Its Associated Factors

\begin{tabular}{|l|c|c|c|}
\hline \multicolumn{1}{|c|}{$\begin{array}{c}\text { Independent } \\
\text { Variable }\end{array}$} & Depression & $\begin{array}{c}\text { No } \\
\text { Depression }\end{array}$ & N=234 \\
\hline Age of dentists & & & \\
\hline 24-30 years & 72 & 49 & 121 \\
\hline 31-40 years & 26 & 20 & 81 \\
\hline$>41$ Years & & & 32 \\
\hline Years Since Graduation & 59 & 42 & 101 \\
\hline$<5$ years & 69 & 27 & 96 \\
\hline$>5$ years & 31 & 6 & 37 \\
\hline$>10$ years & 85 & 42 & 127 \\
\hline Marital Status & 74 & 33 & 107 \\
\hline Single & & & \\
\hline Married & & & 121 \\
\hline $\begin{array}{l}\text { Average number of } \\
\text { working hours per week }\end{array}$ & 77 & 44 & 113 \\
\hline$<40$ hours per week & 82 & 31 & \\
\hline$>40$ hours per week & & & \\
\hline
\end{tabular}

Graph 1: Gender and Depressrion

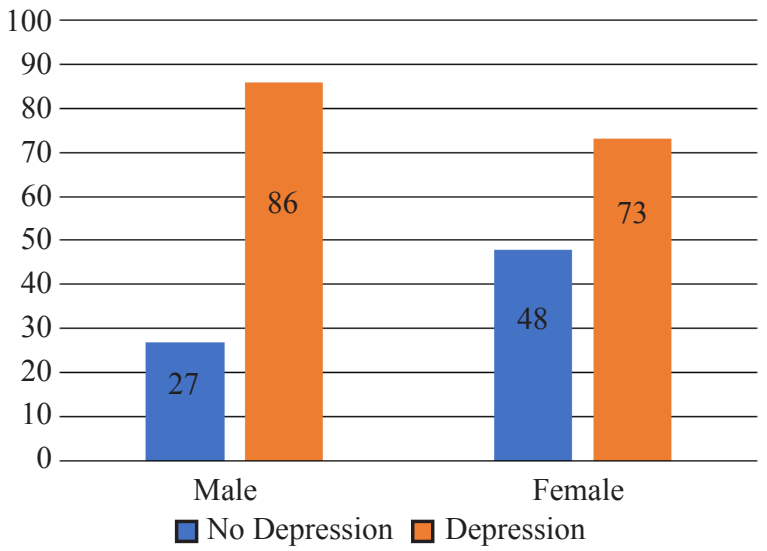

Graph 2: Working Place and Depression

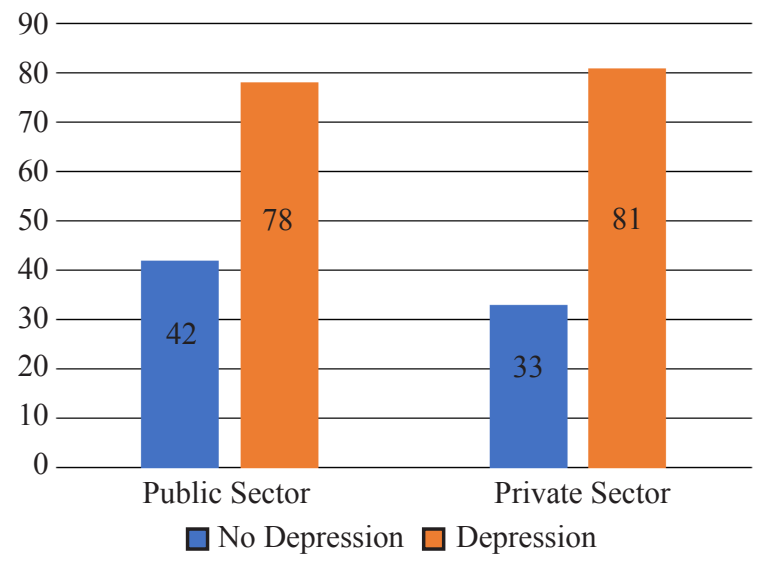

compared with the UK adult (39\%) population. ${ }^{23}$ According to the study conducted amongst Yemeni dentists; $22.2 \%$ dentists had depressive symptoms ${ }^{19}$ and in nursing staff the ${ }^{24}$ reported incidences of anxiety and depression were $25 \%$; another study reported ${ }^{25} 27.8 \%$ of dentists were anxious and depressed. The reported prevalence of stress among dentists in Kerman was $58.9 \%{ }^{26}$ Similar results have been reported in several studies among general dentists in the UK $(68.4 \%)^{27}$, dentists in Denmark (59.7\%) ${ }^{18}$ and orthodontists in Morocco (44\%). ${ }^{18}$

Although in our study; there were more females (51.7\%) as compare to male $(48.3 \%)$ but $(76.1 \%)$ males were found to be more depressed than female dentists. These results were opposite to the study conducted among doctors in Lahore (Pakistan) which revealed that female doctors were more anxious then male doctors and the impact of gender on anxiety scores was significant $(p-0.002)$ by using Hospital Anxiety Depression Score (HADS). ${ }^{1}$ According to the study conducted in Yemen; gender of dentists have insignificant difference in occupational stress score which was due to similar stressors and working environment for male and female dentists in Yemen ${ }^{19}$ and this finding mirrored a study in $\mathrm{Kerman}^{28}$. There were multiple studies; revealed that females were more depressed and anxious as compare to males. ${ }^{29}$ Conversely female Irish dentists were observed having more stressed than males. ${ }^{30}$ In 2004; one of the study conducted on family practitioners of Karachi revealed that mental and physical health of female doctors were significantly more affected by stress and community-based studies from Pakistan also divulged that depression and anxiety was widespread more among female practitioners. ${ }^{14}$ Multiple studies also reported similar results among female dentists in Germany, Greece, United States, Spain, and Brazil. ${ }^{8}$ These results indicate that women have a significantly higher prevalence of depression compared with men. This is due to the emotional differences between the two sexes and the aforementioned cultural responsibilities of Turkish women. ${ }^{31}$ Several studies depicted that female doctors have six times higher risk of developing depression and anxiety ${ }^{6}$ psychological distress and suicidal ideation ${ }^{31}$ than male doctors according to the study conducted in Karachi. ${ }^{3}$ BDA research report of 2014 expressed that high job stressed were reported by men and this difference was not significant in that report. ${ }^{23}$ There were ample literature evidenced the similar results like our study that apparently males are more depressed then females. ${ }^{31}$

In this study, anxiety and depression score was more higher in 24-30 years of dentists and the P-value was 0.014 when comparing all three age stratum of dentists and these results were congruent with another study conducted in which less than 30 years of dentists were more depressed than older dentists ${ }^{19}$ because of lack of experience, emotional exhaustion, new job hunting, competition and these results were also similar with study of Bourassa and Baylard ${ }^{19}$. According to the report regarding the levels of personal wellbeing among UK Dentists revealed that stress level related to work was noteworthy among middle aged dentists and there were not remarkable differences between job related stress with age, 
gender or marital status. ${ }^{23}$

In this study, majority of unmarried/single dentists were found to be more depressed but statistically insignificant difference was found at P-value of 0.385 than married dentists. These results were in harmony with the study conducted in Yemni Dentists ${ }^{19}$ in addition to the depersonalization and personal accomplishment score was higher among single dentists according to the study conducted among Turkish dentists ${ }^{30}$. According to the study conducted among doctors in Lahore; Pakistan, marital status has insignificant impact on anxiety and depression on Hospital anxiety depression score (HADS). ${ }^{1}$

The results of our study depicted that depression was highest among the dentists with more than five years of working experience as compare to other groups in this study; $p$ value was 0.010 and these results were analogous with one of the study ${ }^{25}$ in which $\mathrm{P}$ value was 0.001 .According to the study in 2016; general dental practitioners who had less than 10 years of experience were more stressed then those dentists who were much experienced (20 years). ${ }^{26}$ Earlier studies demonstrated the analogous results that experience is an important factor to control and manage the level of stress. ${ }^{26}$ Clinical experience has an impact over reduction of stress as lack of experience is recognized as anxiety of making mistakes and lack of expertise to handle patients. ${ }^{26,31}$ One of the study conducted in Lahore that doctors with lesser service years were more depressed, while total serving years had no significant impact on anxiety scores. ${ }^{1}$ In United Kingdom, senior medical staff had higher levels of psychological stress and anxiety. ${ }^{23}$ In another study, $50 \%$ of junior doctors suffered from emotional disturbance. ${ }^{15}$

Substantial numbers of dentists from Karachi were depressed than the dentists from Rawalpindi and Islamabad ${ }^{15}$ possibly due to competitive job market, law and order conditions of the city and transportation (congested traffic routes due to construction of overhead bridges which covered the entire metropolitan city of Karachi). Job security has a strong association with depression and anxiety. In this ongoing study; the depression was higher among the dentists who worked in private sector $(71.05 \%)$ as compare to the dentists who worked in public sector and these results were congruent with the study of NM Al Zubair et al. ${ }^{19}$ There was an unmet need to educate the dentists with the coping strategies as to combat with this huge burden of mental disorders.

There were multiple strengths and limitations of this study. Utilization of AKUADS study tool was the strength of this study. Conversely this study is unique as no such study has been conducted in Karachi to assess the depression and anxiety among dentists. Sample technique was also the limitations of this study and the results from our sample cannot be deduced to the wider population of dentists in Karachi, Pakistan. It is recommended that different types of stressors should be incorporated in the questionnaire so that mental health promotion and mental disorders preventive strategies would be formulated by targeting the type of stresses. This is also recommended that stress management together with personal and professional awareness training should be included in the undergraduate curriculum so that threats to mental and social wellbeing, which might occur during the professional life, can be avoided or addressed. Further research and analysis may yield more prolific results, helping us to formulate guidelines to screen anxiety and depression in dentists, and deal with suffers more appropriately and at early stages. Healthy dentists can warranty explicit oral health care delivery.

\section{CONCLUSION:}

The study rendered substantial data about unexpectedly high frequency of anxiety and depression among the sample of dentists from Karachi. It was inferred from the study that experience in professional field, age of dentists, more than 40 hours working per week, marital status and working in private sector were the factors influencing anxiety and depression among the dentists of Karachi.

\section{REFERENCES:}

1. Atif K, Khan HU, Ullah MZ, Shah FS, Latif A. Prevalence of anxiety and depression among doctors; the unscreened and undiagnosed clientele in Lahore, Pakistan. Pakistan journal of medical sciences. 2016; 32(2):294.

2. Institute of Medicine. Neurological, psychiatric, and developmental disorders: meeting the challenge in the developing world. Washington, DC: National Academy Press, 2001.

3. Khuwaja AK, Qureshi R, Azam SI. Prevalence and factors associated with anxiety and depression among family practitioners in Karachi, Pakistan. JPMA. The Journal of the Pakistan Medical Association. 2004; 54(2):45-9.

4. Seligman MEP, Walker EF, Rosenhan DL. Abnormal Psychology (4th Ed.). New York: W.W. Norton \& Company.

5. Salmans S. Depression: Questions You Have - Answers You Need. Allentown PA: People's Medical Society; 1997.

6. Saraceno B. A landmark year for world mental health 2001. J Coll Physicians Surg Pak. 2001; 11:190-191.

7. Robert E, Charmine 1. Stress, Burn out, Anxiety and depression among Dentists. JOURNAL OF American Dental Association 2004; 9135: 788-94

8. Carneiro et al. Burnout syndrome: Evaluation in dentists in the city of Fortaleza, Brazil. RSBO. 2013;10(3):266-271

9. George JM, Milone CL, Block MJ, Hollister WG. Stress management for the dental team. Philadelphia: Lea \& Febiger; 1986:03-20.

10. Wallace JE. Mental health and stigma in the medical profession. Health. 2012; 16(1):03-18.

11. Arnetz BB. Psychosocial challenges facing physicians of today. SocSci Med.2001;52:203-13.

12. Gong Y, Han T, Chen W, Dib HH, Yang G, Zhuang R, et al. Prevalence of anxiety and depressive symptoms and related risk factors among physicians in China: a cross-sectional study. PloS one. 2014; 9(7):e103242. 
13. National Institute of Mental Health.Depression. Available from: http://www.nimh.nih.gov/ health/ topics/ depression/ index.shtml.Accessed on June 2017.

14. Ali BS, Rahbar MH, Naeem S, Tareen AL, Gul A, Samad L. Prevalence of and factors associated with anxiety and depression among women in a lower middle class semi urban community of Karachi, Pakistan. J Pak Med Assoc. 2002; 52(11):513-517.

15. Azad AA, Qurrat-ul-ain SH, Nisar N, Ashfaq M, Munir A, Ahmed A, Saeed MH. Prevalence of stress and burnout among dentists of Rawalpindi and Islamabad. Pakistan oral \& dental journal. 2013; 33(3).

16. Khan A, Hafsa Alvi et al. The prevalence of stress and associated factors in dentists working at Islamic International Dental Hospital, Islamabad. PODJ 2010; 30(2): 521-525.

17. World Health Organization. Mental Health [Internet]. WHO. [Cited 2017 Mar 23]. Available from: http://www.who.int/ mental_health/en/

18. Erdur B, Ergin A, Turkcuer I, Parlak I, Ergin N, Boz B. A study of depression and anxiety among doctors working in emergency units in Denizli, Turkey. Emerg Med J. 2006;23(10):759-763

19. Al-Zubair NM, Sultan Al-ak'hali M, Ghandour IA. Stress among dentists in Yemen. The Saudi Journal for Dental Research. 2015; 6(2):140-5.

20. Ali KF, Fatima A, Ilyas F. Impact of Anxiety and Depression on Temporomandibular Joint Disorders among Sample of Dental Undergraduates of Karachi. JPDA. 2016; 25(4):144.

21. SPSS for Windows Base Version 23.0.0 Chicago: SPSS Inc, 2015.
22. Rabbani F, Raja FF.The minds of mother's maternal mental health in an urban squatter settlement of Karachi. J Pak Med Assoc 2000; 50306-12.

23. Kemp M, Edwards H. Levels of Personal Well-being among UK Dentists. London: British Dental Association. 2014 Jan.

24. Abbas MA, Abu Zaid LZ, Hussaein M, Bakheet KH, Alhamdan NA. Anxiety and depression among nursing staff at King Fahad Medical City, Kingdom of Saudi Arabia. J Am Sci. 2012;8(10):778-94.

25. PRASAD M, PATTHI BR, SINGLAA, GUPTA R, KRISHNA J, KUMAR IA, DHAMA K, NIRAJ LK. Assessment of Anxiety and Depression among dental practitioners-An Exploratory Cross-sectional Study. Chance. 142:58-9.

26. Pouradeli S, Shahravan A, Eskandarizdeh A, Rafie F, Hashemipour MA. Occupational Stress and Coping Behaviours among Dentists in Kerman, Iran. Sultan Qaboos University Medical Journal. 2016; 16(3):e341.

27. Myers. HL, LB Myers. It is difficult being a dentist: stress and health in the general dental practitioner. Br Dent J 2004; 197: 89-93

28. Kumar S, Dagli RJ, Mathur A, Jain M, Prabu D, Kulkarni S. Perceived sources of stress amongst Indian dental students. Eur J Dent Educ 2009;13(1):39-45.

29. Rogers C, Malone KM. Stress in Irish dentists: Developing effective coping strategies. J Ir Dent Assoc 2009; 55:304-7.

30. Huri M, Baðýp N, Eren H, Umaroðlu M, Orhan K. Association between burnout and depressive symptoms among Turkish dentists. Journal of Dental Sciences. 2016; 11(4):353-9.

31. Harrison D. Doctors more likely to get depressed. The Age National Newspaper. (October 7, 2013). 